\title{
Dentistry Goes Digital: A Cad-Cam Way- A Review Article
}

\author{
Aalap Prajapati ${ }^{1}$, Anchal Prajapati ${ }^{2}$, Dhawal R.Mody ${ }^{3}$, Anuraag B.Choudhary ${ }^{4}$ \\ ${ }^{1}$ Department of Prosthodontics, Pramukh Swami Medical College, Karamsad, Anand, India-388325 \\ ${ }^{2}$ Department of Periodontics, Pramukh Swami Medical College, Karamsad, Anand, India-388325 \\ ${ }^{3}$ Department of Periodontics, VSPM's Dental College, Hingna road, Nagpur, India- 440019 \\ ${ }^{4}$ Department of Oral Medicine, VSPM's Dental College, Hingna road, Nagpur, India- 440019
}

\begin{abstract}
Computer Aided Design/Computer Aided Manufacturing (CAD/CAM) was first introduced to dentistry in the mid-1980s.Both chairside and chair side-laboratory integrated procedures are available for $C A D / C A M$ restoration fabrication. In selecting which procedure to follow, consideration should be given to esthetic demands, chairside time, and laboratory costs, number of visits and convenience and return on investment associated with CAD/CAM equipment. Depending on the method selected, CAD/CAM ceramic blocks available for restoration fabrication include leucite reinforced ceramics, lithium disilicate, zirconia, and composite resin. In order to determine which type of ceramic to use, the practitioner must take into account esthetics, strength, and ease of customizing milled restorations. This article provides an overview of various CAD/CAM systems.
\end{abstract}

Keywords: CAD-CAM, leucite reinforced ceramics, zirconia

\section{Introduction}

The latest innovations in TECHNOLOGY made almost all things possible in this world. The lost-wax precision casting of gold alloys, dough modelling and curing of acrylic resins and powder sintering of dental porcelains were originally developed for dentistry and are well established as conventional dental laboratory technologies. It is without doubt that high quality dental devices can routinely be fabricated through the collaboration of dentist and dental technicians. Nevertheless, dental laboratory work still remains to be labourintensive and experience dependent. ${ }^{1}$ The laboratory technician's primary role in dentistry is to perfectly copy all of the functional and aesthetics parameters that have been defined by the dentist into a restorative solution. It is an architect/builder relationship. Throughout the entire restorative procedure, from initial consultation through treatment planning, provisionalization and final placement, the communication routes between the dentist and the dental technician require a complete transfer of information pertaining to existing, desired and realistic situations and expectations to and from the clinical environment. Functional components, occlusal parameters, phonetics and aesthetics are just some of the essential information which dental technician completes with his skills and experience. As dentistry evolves into the digital world of image capture, computer design, and the creation of dental restorations through robotics, the dental laboratory must evolve as well. Computer-aided design/Computer-aided manufacturing $(\mathrm{CAD} / \mathrm{CAM})$ restoration gives us that option. The laboratory is no longer a place; it is instead to a large degree, virtual and fluid entity. ${ }^{2}$ It is hence no doubt to call CAD/CAM a Virtual Laboratory. (Fig. 1)

Research and development of dental CAD/CAM systems has been actively pursued world-wide since 1980's due to continuous efforts of three pioneers namely, Dr. Francois Duret, Dr. Werner Mormann and Dr. Andersson. ${ }^{3}$

\section{General Principles Of Cad/Cam Technology}

The developments that have fuelled the growth of the CAD/CAM dentistry are mostly based on the major developments in microelectronics, which have helped in leapfrogging the capabilities. For convenience in understanding, $\mathrm{CAD} / \mathrm{CAM}$ system is divided into $\mathrm{CAD} / \mathrm{CAM}$ hardware and $\mathrm{CAM} / \mathrm{CAM}$ software. ${ }^{4}$

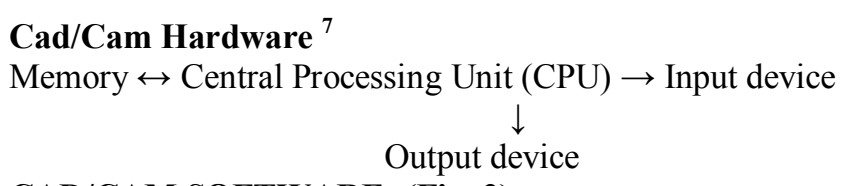

$$
\text { Output device }
$$

CAD/CAM SOFTWARE: (Fig. 2)

Prosthesis is fabricated by $\mathrm{CAD} / \mathrm{CAM}$ technology through three basic steps ${ }^{8}$ : 


\section{Digitization}

The digitizing accuracy is a major factor, which has an influence on the fit of fixed restoration. Currently the data acquisition is either performed directly in the patient's mouth (intraoral) or indirectly after taking an impression and fabricating a master cast (extraoral). Regardless of the digitizing mode applied, clinical parameters, e.g. saliva, blood, movements of the patient, might affect the reproduction of teeth.

Intraoral digitization allows the dental care provider to directly obtain the data from the prepared teeth. Thus, taking an impression and fabricating a cast model are no longer necessary. Titanium dioxide or magnesium oxide powder has to be applied to the glossy, lucent tooth surfaces in order to avoid reflections and to create a measurable surface. The powder layer applied to the tooth surface results in an additional thickness of $13-85 \mu \mathrm{m}$. An in vitro study showed a higher accuracy of the extraoral digitization than in case of intraoral one ${ }^{9}$.

There are two methods available for extraoral digitization.

1. Contact digitization

2. Optical digitization

Accuracy is the degree of veracity, e.g. how well the measured value represents the 'truth', while precision is the degree of reproducibility, e.g. the repeatability of the measurement system. Ideally a measurement device is both accurate and precise, with measurements all close to and tightly clustered around the true value ${ }^{10}$.

\section{Mathematical Processing Or Computer-Aided Designing (Cad). (Fig. 3-7)}

A three-dimensional image of the die is produced over the screen and can be rotated for observation from any angle. Current software allows the crown form to be designed by selecting the proper tooth element from the library and then modelling the crown to fit in with the remaining dentition.

\section{Computer-Aided Milling (Cam) ${ }^{5}$}

The CAM technologies can be divided in three groups according to the technique used:

a. Subtractive technique from a Solid Block - The CAM technique most commonly applied in manufacturing frameworks for single crowns and FPDs is to cut the contour out of an industrially prefabricated solid block of different materials. The size of the material blocks available for the milling units limits the size of the FPDs.

b. Additive technique by applying Material on Die - Here in this technique Alumina or Zirconia is dry pressed on the die and the temperature is raised to a temperature similar to the presintering state. At this stage, enlarged and porous coping is stable. Its outer surface are milled to the desired shape and coping, removed from die, and sintered into the furnace for firing to full sintering.

c. Solid free form fabrication - This category includes new technologies originating from the area of Rapid Prototyping (RP), which have been adapted to the needs of dental technology. A second technology originating from rapid prototyping is the stereolithography (Perfactory, Delta Med, Frieberg, Germany). In this technique, the restoration is produced from light sensitive plastic, which can be converted into any desired alloy with the casting technique. Occlusal splints and diagnostic templates for oral implantology can also be produced with this technique. The third technique is the selective laser sintering, where sinterable powder materials are built up to form 3-D restorations.

The milling device consists of two major units: (1) rotatory drilling element with interchangeable bores of different shapes and diameter and computerized velocity (2) a mobile platform to which the dummy is fixed. The computerized platform can be moved in three dimensions, allowing precise milling of the desired coping.

Milling consists of three steps: (1) rough milling inside the coping to remove the bulk of the material (2) fine inside milling to increase accuracy (3) rough external milling.

\section{Production Factors}

The range of accuracy for each step is $3-5 \mu \mathrm{m}$ for digitizing, less than $5 \mu \mathrm{m}$ for mathematical processing and $15-25 \mu \mathrm{m}$ for milling. Overall accuracy can be increased by carrying out the individual steps more slowly.

Theoretically, the mean working times of the different procedures are 3-8 minutes for digitizing, 8-12 minutes for mathematical processing and 20-25 minutes for milling. It should be emphasized that the actual working time is approximately 10 minutes, mainly for digitizing.

\section{Commercially Available Cad/Cam Systems}

$\mathrm{CAD} / \mathrm{CAM}$ systems may be categorized as either in-office or laboratory systems. Among all dental $\mathrm{CAD} / \mathrm{CAM}$ systems, CEREC is the only manufacturer that provides both in-office and laboratory modalities. Laboratory CAD/CAM systems have increased significantly during the last 10 years and include DSC Precident, Procera, CEREC inLab, Lava and many others. 
Cicero System ${ }^{11}$

Cerec System ${ }^{13}$

Evolution Of Cerec System ${ }^{12}$

$\begin{array}{lll}\text { YEAR } & \text { HARDWARE } & \begin{array}{l}\text { SOFTWARE } \\ \text { CAPABILITY } \\ \text { Two dimensional }\end{array} \\ 1980 & \text { Basic concept } & \text { Two dimensional } \\ 1985 & \text { CEREC 1 } & \text { Two dimensional } \\ 1988 & \text { CEREC 1 } & \text { Two dimensional } \\ 1994 & \text { CEREC 2 } & \text { Two dimensional } \\ 2000 & \text { CEREC 3 \& inLab } & \text { Three dimensional } \\ 2003 & \text { CEREC 3 \& inLab } & \text { Three dimensional } \\ 2005 & \text { CEREC 3 \& inLab } & \end{array}$

\section{Figures And Tables}

\section{RESTORATION TYPE \\ DEVELOPER}

Inlays

First chairside inlay

Inlays(1), Onlays(2) and

Veneers(3)

1-3, partial(4) and full(5) crowns, copings $(6)$

1-6 and three-unit bridge

frames

1-6 and three \& four-unit bridge frames

1-5 and automatic virtual Sirona occlusal adjustment
Mormann (University of Zurich) and Brandestini (Brandestini Instruments, Zurich) Mormann and

Brandestini

Mormann

Brandestini

Sirona

Germany)

Sirona

Germany)

Sirona

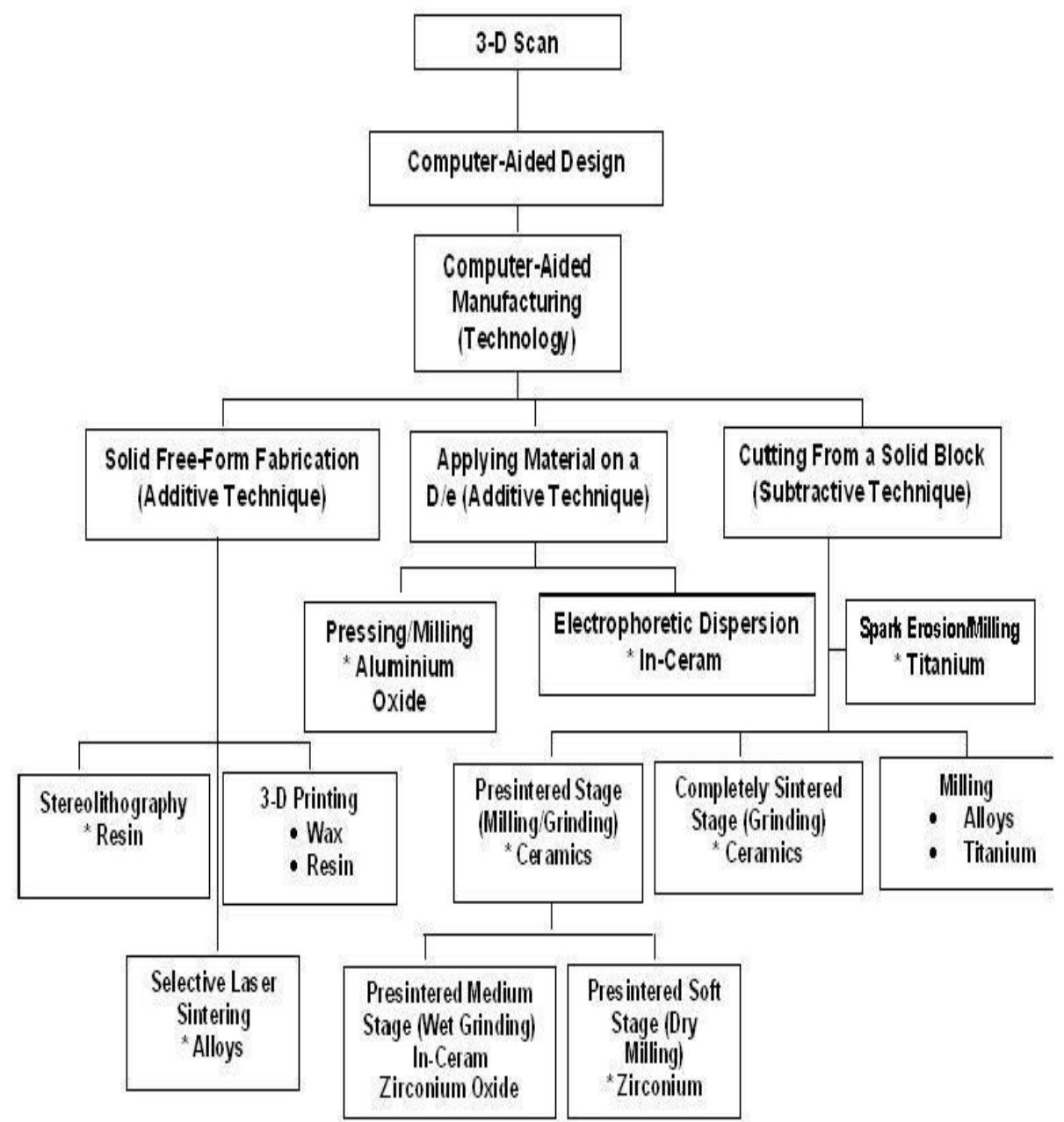

Fig. 1 An overview of the CAD/CAM systems available today in dentistry. 


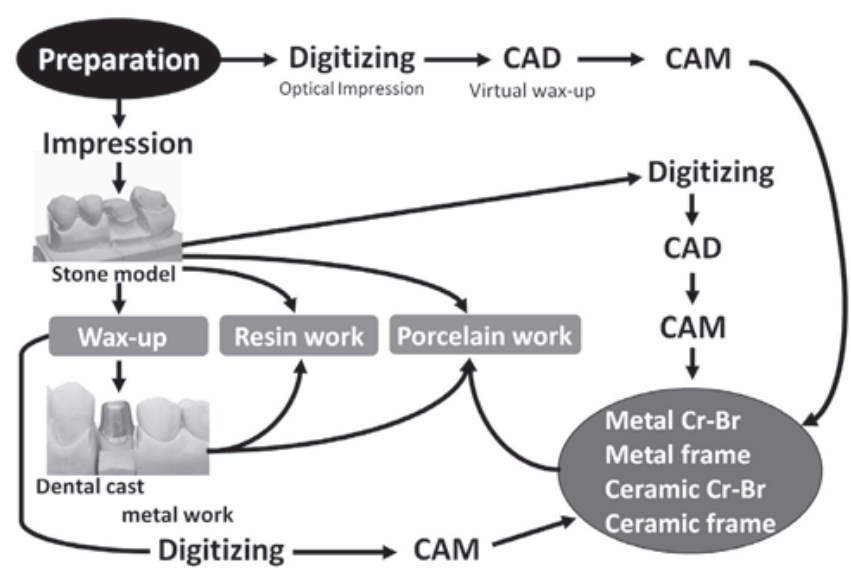

Fig. 2 PATHWAY THE CURRENT CAD/CAM SYSTEM USES FOR FIXED PROSTHESIS FABRICATION

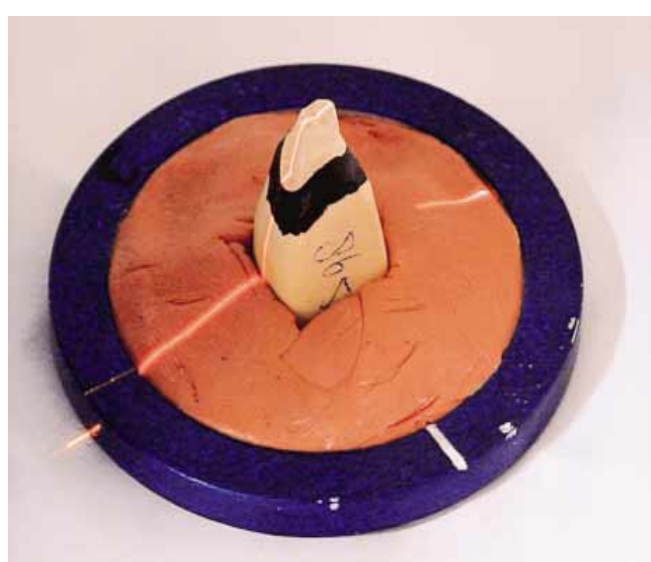

Fig. 3 Die With Black And White Contrast

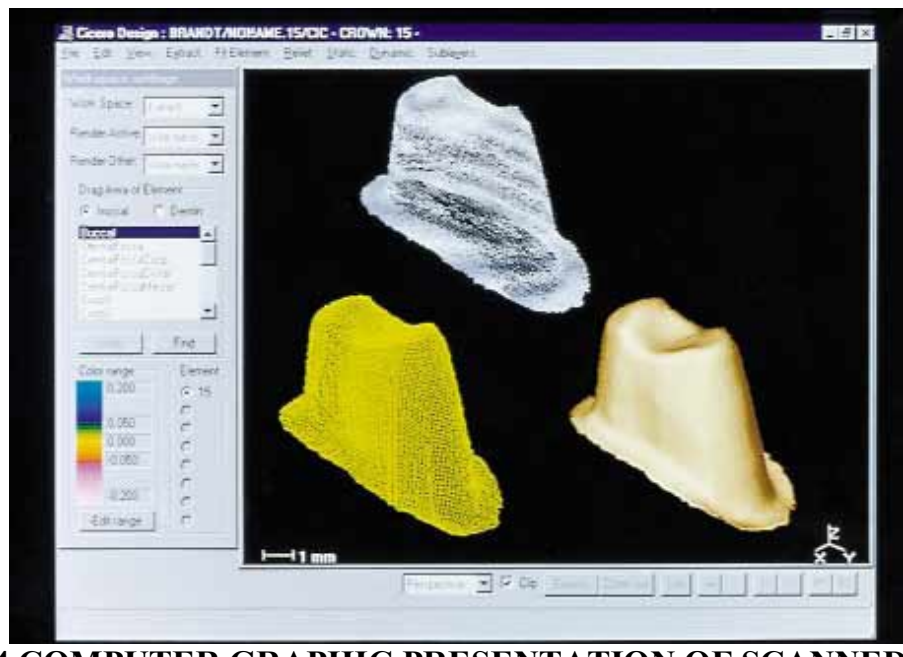

FIG. 4 COMPUTER GRAPHIC PRESENTATION OF SCANNED DIE 


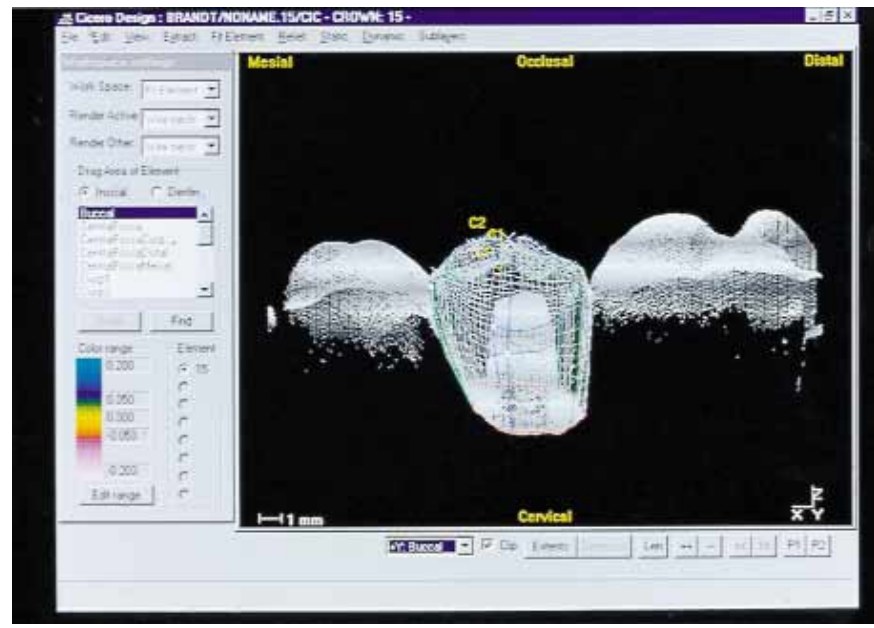

FIG. 5 DESIGNED CROWN PLACED IN ROW

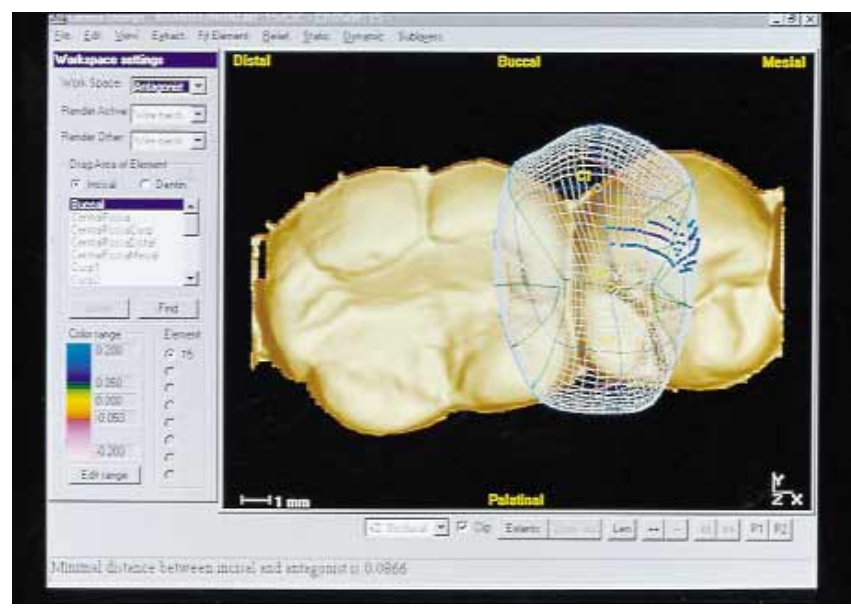

FIG. 6 DESIGN CROWN IN OCCLUSION

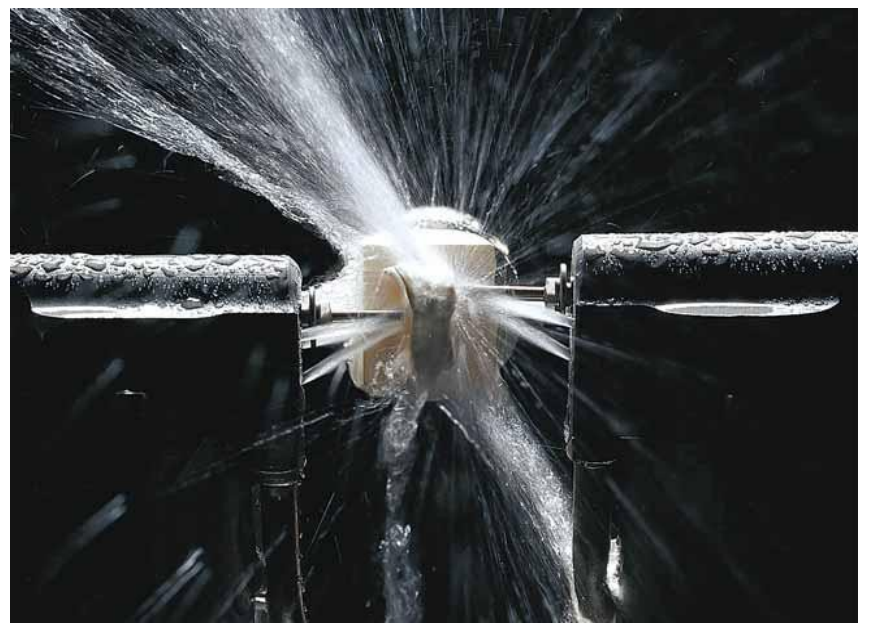

FIG. 7 MILLING PROCEDURE 


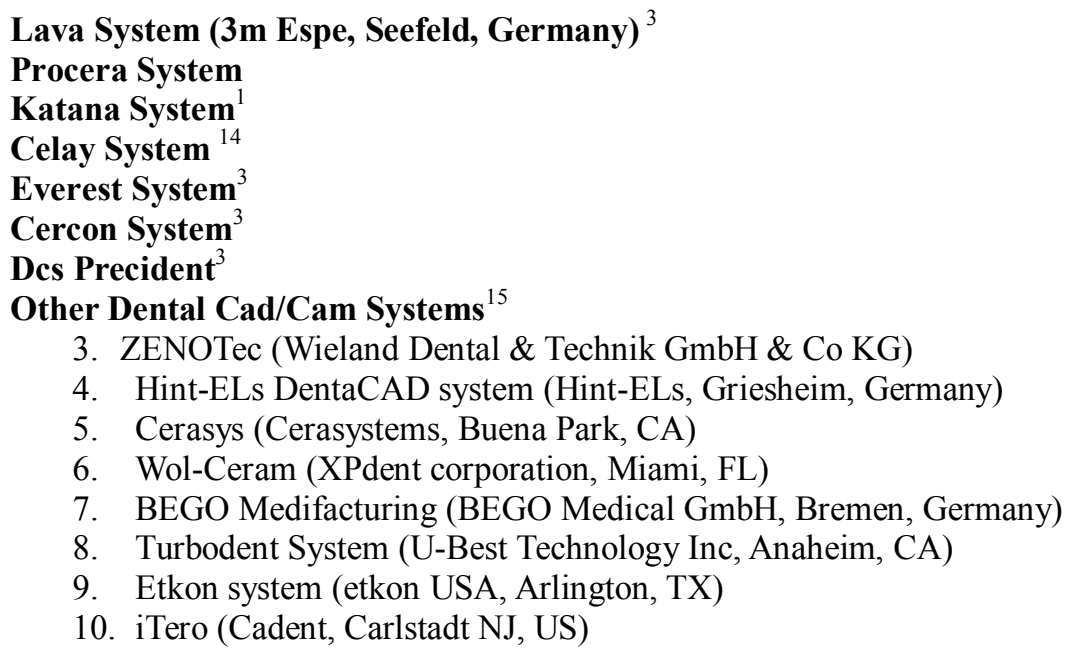

\begin{tabular}{|c|c|c|c|c|c|}
\hline \multicolumn{6}{|c|}{ Comparision Of Common Dental Cad/Cam Systems ${ }^{3}$} \\
\hline SYSTEM & MARKET & PROCESS & \multicolumn{3}{|c|}{ Comparision Of Common Dental Cad/Cam Systems } \\
\hline & LAUNCH & CENTRE & MECHANISM & & \\
\hline Cerec 3 & 2000 & Chairside & Optical & $\begin{array}{l}\text { Yes, custom design and } \\
\text { database }\end{array}$ & $\begin{array}{l}\text { Fully } \\
\text { automatic }\end{array}$ \\
\hline Cerec InLab & 2001 & Dental Lab & Laser & $\begin{array}{l}\text { Yes, custom design and } \\
\text { database }\end{array}$ & $\begin{array}{l}\text { Fully } \\
\text { automatic }\end{array}$ \\
\hline DCS Precident & 1989 & Dental Lab & Optical & $\begin{array}{l}\text { Yes, custom design and } \\
\text { database }\end{array}$ & $\begin{array}{l}\text { Fully } \\
\text { automatic }\end{array}$ \\
\hline Procera & 1993 & $\begin{array}{l}\text { New Jersey or } \\
\text { Sweden }\end{array}$ & Manual & $\begin{array}{l}\text { Yes, custom design and } \\
\text { database }\end{array}$ & $\begin{array}{l}\text { Fully } \\
\text { automatic }\end{array}$ \\
\hline Lava & 2002 & Dental Lab & Optical & $\begin{array}{l}\text { Yes, custom design and } \\
\text { database }\end{array}$ & $\begin{array}{l}\text { Fully } \\
\text { automatic }\end{array}$ \\
\hline Everest & 2002 & Dental Lab & Optical & $\begin{array}{l}\text { Yes, custom design and } \\
\text { database }\end{array}$ & $\begin{array}{l}\text { Fully } \\
\text { automatic }\end{array}$ \\
\hline Cercon & 2001 & Dental Lab & Laser & No & $\begin{array}{l}\text { Fully } \\
\text { automatic }\end{array}$ \\
\hline
\end{tabular}

\section{Advantages And Disadvantages Of Cad/Cam Technology}

Advantages:

The advantages of using CAD/CAM technology can be summarized as: ${ }^{1,16}$

1. Applications of new materials - High strength ceramics that are expected to be the new materials for FPDs frameworks have been difficult to process using conventional dental laboratory technologies. Therefore, this challenged to apply CAD/CAM processing. Due to successful use of all-ceramic crowns, all ceramic systems have become a viable treatment option ${ }^{6}$.

2. Time effectiveness

3. Reduced labour

4. Quality control

5. Patients often experience irritation in, sensitivity in and/or difficulty in cleaning temporized teeth. With this system temporaries become obsolete, thus making uncomfortable and unaesthetic transition times a thing of past. Also, there is diminished chance of bacterial invasion during this phase, decreased pulpal stress resulting from excessive cleaning, drying or trauma, and decreased need for the additional tooth manipulation.

6. It is not always possible for the dentist to create a full arch of precisely parallel preparations. The computer can calculate, design, and build the copings, which can be cemented to yield a well-seating bridge.

7. Scanning an image and viewing it on a computer screen allows the dentist to review the preparation and impression, and make immediate adjustments to the preparation and/or retake the impression if necessary, prior to its being sent to the milling unit or a laboratory. This ensures no calls from a laboratory that the impression is defective. This review, as well as seeing a preparation multiple times its normal size on a screen, can result in improved preparations.

8. A digital impression also means that patients do not have to have impression material and trays used, saving them discomfort.

9. By using zirconium as implant abutment, light transmission into the gingival sulcus is allowed, thus preventing the grey of opaque metal parts from showing through peri-implant tissue. 
10. Latest innovation in $\mathrm{CAD} / \mathrm{CAM}$ system allows occlusion to be viewed and developed in dynamic state.

\section{Disadvantages: ${ }^{1,16}$}

1. The primary consideration in a CAD/CAM purchase is the length of the learning curve, which may range from a few days to several months and may result in the loss of office production and loss of patient treatment time.

2. Other major problem is the potential for the dental team to resist the system's use and the clinician's lack of confidence in using a computerized system.

3. Capital costs of these systems are quite high and rapid large scale production of good quality restoration is necessary to achieve financial viability.

4. Matching the patient's tooth shade to the blocks of materials used to fabricate the restorations can be a challenge to the dentist initially.

5. Some $\mathrm{CAD} / \mathrm{CAM}$ system relies on margin capture for digitization, thus making subgingival margin capture challenging.

6. $\mathrm{CAD} / \mathrm{CAM}$ is ever advancing technology. Upgrades and updates are to be expected. The existing software takes no time to become obsolete. It is wise to question how long the technology has been on the market and how soon a revision will become available. Thus, the dentist may need to budget for monthly expenses for technical support and software upgradation.

\section{Conclusion}

With growing awareness of aesthetics and biocompatibility, patients increasingly request metal free restorations. Due to successful use of all-ceramic crowns, all ceramic systems have become a viable treatment option $^{7}$. These newer materials also are more wear resistant nearly like enamel and are strong enough for full crowns and bridges. The application of dental CAD/CAM systems is promising, not only in the field of crowns and FPDs, but also in other fields of dentistry. There is no doubt that the application of CAD/CAM technology in dentistry provides innovative, state-of-art dental service, and contributes to the health and Quality of Living of people in aging societies. As Duret concluded "The systems will continue to improve in versatility, accuracy, and cost effectiveness, and will be a part of routine dental practice in coming time."33

\section{References}

[1]. Takashi M, Yasuhiro H, Jun K, Soichi K. A review of dental CAD/CAM: current status and future perspectives from 20 years of experience. Dental Materials Journal, 2009: 28(1): 44-56.

[2]. Lee C, Alex T. CAD/CAM Dentistry: A new forum for dentist-technician Teamwork. Inside Dentistry, Sep 2006: vol 2, Issue 7 .

[3]. Perng-Ru Liu. Panorama of Dental CAD/CAM Restorative systems. Compedium, July 2005: 26(7): 507-512.

[4]. Angeles M, Salvador A, Mariano A, Maria P. CAD/CAM dental systems in implant dentistry: Update-Med Oral Patol Oral Bucal: March 2009 1:14(3), E141-5.

[5]. Candice Z, Shermian A, Richard M, John D. Rapid prototyping technique for creating a radiation shield. J Prosth Dent, April 2007: 97(4): 236-41.

[6]. Vigolo P, Odont D, Fonzi F. J Prosthodontics, 2008: 17: 621-26.

[7]. CAD/CAM: Principles, practice and manufacturing management. $2^{\text {nd }}$ edition: Part-I.

[8]. Samet N, Benjamin R, Shaul G, Noah S. A CAD/CAM system for the production of metal copings for porcelain fused to metal restorations. J Prosth Dent 1995: 73(5): 457-463.

[9]. Sebastian Q, Heike R, Ralph G. Direct mechanical data acquisition of dental impressions for the manufacturing of CAD/CAM restorations. J of Dentistry 2007: 35: 903-908.

[10]. Persson A, Matts A, Agneta O, Gunilla S. Computer aided analysis of digitized dental stone replicas by dental CAD/CAM technology. Dental Materials 2008: 24: 1123-1130.

[11]. Jef M, Simon V, William J, Carel D. The CICERO system for CAD/CAM fabrication of full-ceramic crowns. J Prosth Dent 2001: 85(3): 261-267.

[12]. Mormann W. The evolution of the CEREC system. JADA 2006: 137: 7S-13S.

[13]. Wang WC, McDonald A. Petrie A, Setchell D. Interface dimensions of CEREC-3 MOD onlays. Eur J Prosthodont Rest Dent 2007: 15(4): 183-189.

[14]. Rinke S, Huls A, Jahn L. Marginal accuracy and fracture strength of conventional and copy-milled all ceramic crowns. Int J Prosthodont 1995: 8: 303-310.

[15]. Feuerstein P. New changes in CAD/CAM: Part 2 Lab systems. Inside dentistry. March 2007: 82-86.

[16]. Paul F, Sameer P. CAD/CAM and digital impressions. Catalogue of the course organized by Pennwell. 